\section{Crop Load Management Does Not Consistently Improve Crop Value of 'Sweetheart'/'Mazzard' Sweet Cherry Trees}

\author{
Todd C. Einhorn ${ }^{1}$, Debra Laraway, and Janet Turner
}

AdDitional Index wORDs. Prunus avium, thinning, source-sink relationships, return bloom, fruiting density, crop load adjustment, bud removal

\begin{abstract}
SuMMARY. The effect of crop load level on vegetative growth, fruit growth, yield, fruit quality, surface pitting, crop value and return bloom was studied over a 2 -year period on 9- and 10-year-old 'Sweetheart' /'Mazzard' sweet cherry (Prunus avium) trees. In early spring, whole-tree crop loads were adjusted to two different levels by removal of reproductive buds (either $50 \%$ or all but one) from spurs and compared with an unthinned control. In 2009, heavy crop loads of unthinned trees reduced fruit size by 30 days after full bloom (DAFB). At harvest, fruit diameter of thinned treatments was increased $22 \%$ and $27 \%$ compared with unthinned fruit. Fruit quality attributes [soluble solids concentration (SS), fruit firmness, and total acids (TA)] were significantly greater for thinned treatments. Thinned treatment yields were reduced $40 \%$ to $54 \%$ relative to unthinned trees, with greater percentages of fruit in large size classes. Despite significantly fewer fruit per tree, moderately thinned trees had a higher estimated crop value ( $\$ 142$ per tree) than unthinned trees (\$125 per tree). Crop value was lowest for the heavily thinned treatment (\$107 per tree), reflecting overthinning. In 2010, shoot growth was negatively related to crop load level. Fruit growth of unthinned trees was not significantly affected by higher fruit density until 89 DAFB. Yield of 2010 unthinned trees was $87 \%$ of 2009, while thinned tree yields were similar between years. Improved fruit quality and greater percentages of large fruit were observed for thinned treatments in 2010; however, crop value was highest for unthinned trees ( $\$ 190$ per tree), even though $18 \%$ of the fruit were too small for fresh market sale. Surface pitting was unaffected by crop load level in either year. Return bloom (flowers per reproductive bud and reproductive buds per spur) was significantly, negatively related to the prior season's crop load in 2010 and 2011 . In the current sweet cherry pricing structure, higher crop value is associated with large volumes of medium-sized fruit. Thinning to manage crop load of low-medium density, productive 'Sweetheart' / Mazzard' trees will not be an annual requirement, though in heavy fruit set years crop load management will improve crop value.
\end{abstract}

$\mathrm{P}$ rofitability of tree fruit producers is dependent upon consistent, high yields of quality fruit. Over the last decade, sweet cherry producers in the Pacific northwestern United States (PNW) have been transitioning to high-density plantings based on detailed studies showing increased production (Perry et al., 1998; Whiting and Lang, 2004; Whiting et al., 2005b) and the commercial availability of semidwarfing, precocious rootstocks (Kappel and Lang, 2008; Lang, 2000). These rootstocks greatly improve labor efficiency, increase production, and hasten net returns; however, the majority of sweet cherry acreage is planted on highly

Department of Horticulture, Oregon State University, Mid-Columbia Agricultural Research and Extension Center, 3005 Experiment Station Drive, Hood River, OR 97031

${ }^{1}$ Corresponding author. E-mail: todd.einhorn@ oregonstate.edu. vigorous rootstocks at low to moderate densities. There has been little need to manage crop loads in these orchards due to the favorable balance of leaves to fruit resulting from the interaction between low scion precocity and high rootstock vigor. Despite this scenario, high yields from mature, low-density 'Bing' trees adversely impacted fruit quality (Proebsting and Mills, 1981; Spayd et al., 1986). Indeed an inverse relationship between sweet cherry crop load and fruit quality has been documented (Facteau et al., 1983; Proebsting, 1990; Roper and Loescher, 1987; Whiting and Lang, 2004).

Crop load management strategies to maintain fruit size via some form of pre or postbloom flower/fruit thinning has been the subject of recent investigation (Schoedl et al., 2009; Whiting and Ophardt, 2005; Whiting et al., 2006). To date, inconsistent response of fruit to chemical thinning strategies has limited commercial adoption. Presently, the industry largely relies on pruning for crop load management (L. Long, personal communication). Ultimately, the decision to impose a crop load management strategy, and the level to which it is carried out, will depend upon the value of the crop. The potential gross income of sweet cherry production is reliant upon yield, number of fruit per size category, and the price paid per size class.

The self-fertile cultivar Sweetheart is valued for its late-season harvest timing, precocity, and high productivity (Lane and MacDonald, 1996). However, 'Sweetheart' has medium to small fruit size (Lane and MacDonald, 1996) and propensity for surface pitting (B. Bailey, personal communication). Surface pitting of sweet cherry fruit is characterized by collapsed hypodermal cells resulting in sunken, irregular depressions on the surface of the fruit (Porritt et al., 1971). Symptoms are attributed to impact injuries sustained during harvest and postharvest handling operations (Facteau and Rowe, 1979; Thompson et al., 1997), but crop load has been positively correlated with surface pitting of 'Sweetheart' (J.P. Zoffoli, personal communication), as was observed for 'Bing' (Spayd et al., 1986).

\begin{tabular}{llll}
\hline $\begin{array}{l}\text { Units } \\
\text { To convert U.S. to SI, } \\
\text { multiply by }\end{array}$ & U.S. unit & SI unit & $\begin{array}{l}\text { To convert SI to U.S., } \\
\text { multiply by }\end{array}$ \\
\hline 0.4047 & acre(s) & ha & 2.4711 \\
29.5735 & $\mathrm{fl} \mathrm{oz}$ & $\mathrm{mL}$ & 0.0338 \\
0.3048 & $\mathrm{ft}$ & $\mathrm{m}$ & 3.2808 \\
2.54 & inch(es) & $\mathrm{cm}$ & 0.3937 \\
25.4 & inch(es) & $\mathrm{mm}$ & 0.0394 \\
6.4516 & inch & $\mathrm{cm}^{2}$ & 0.1550 \\
0.4536 & $\mathrm{lb}$ & $\mathrm{kg}$ & 2.2046 \\
28.3495 & $\mathrm{oz}$ & $\mathrm{g}$ & 0.0353 \\
1.1161 & $\mathrm{oz} / \mathrm{inch}$ & $\mathrm{g} \cdot \mathrm{mm}^{-1}$ & 0.8960 \\
$\left({ }^{\circ} \mathrm{F}-32\right) \div 1.8$ & ${ }^{\circ} \mathrm{F}$ & ${ }^{\circ} \mathrm{C}$ & $\left(1.8 \times{ }^{\circ} \mathrm{C}\right)+32$ \\
& & &
\end{tabular}


When used in combination with dwarfing rootstocks, heavy fruit set can severely limit both vegetative development and fruit quality of sweet cherry (Edin et al., 1996); a scenario that would likely be amplified given the precocity and high productivity of 'Sweetheart'. Hence, a large portion of 'Sweetheart' acreage in the PNW has been planted at moderate tree densities with vigorous, nonprecocious 'Mazzard' rootstock. An interesting horticultural question is therefore raised: Does the vigorous rootstock 'Mazzard' effectively balance the high productivity and precocity of 'Sweetheart', or could fruit quality, and importantly, crop value be improved by imposing a crop load management strategy? The following study was designed to address this question and determine the effects of crop load on vegetative and reproductive development of 'Sweetheart'/'Mazzard' trees.

\section{Materials and methods}

Plant material and ExPERIMENTAL DESign. Nine-year-old 'Sweetheart' / Mazzard' sweet cherry trees, spaced $14 \times 19 \mathrm{ft}$ (164 trees/ acre) were trained to a multiple leader, open-center architecture at a commercial orchard (Orchard View Farms) located in The Dalles, OR (lat. $45.6^{\circ} \mathrm{N}$, long. $\left.121.2^{\circ} \mathrm{W}\right)$. Soil was a Cherryhill silt loam. Fifteen trees with similar canopy volume and trunk crosssectional area (TCSA) were selected in Mar. 2009 and randomly assigned to one of three crop load treatments in a complete randomized design: (1) control, (2) T1, and (3) T2. With the exception of the control, crop load levels were adjusted by removing reproductive buds by hand in early spring when bud development was about stage 1 (first swelling). Half of the reproductive buds per spur were removed for $\mathrm{T} 1$, and all but one for T2. Bud removal was performed on all spurs of each replication. The vegetative bud was left intact on all spurs. Floral buds on basal sections of 1-year-old wood were not thinned. Otherwise, the experimental trees were managed commercially. The experiment was repeated on the same trees in 2010.

Fruit, SHOOT AND TRUNK GROWTH. Fruit diameter was measured each week on 15 fruit per replication with a digital caliper (VWR
International, West Chester, PA). One fruit per spur was tagged at 20 and 15 DAFB in 2009 and 2010, respectively. Individual fruit were positioned in the instrument perpendicular to the suture, at the widest point. Weekly measurements were performed in the morning to avoid diurnal fluctuation in fruit size. Measurement spurs were randomly selected from 2-year-old wood of shoots occupying similar positions in the canopy.

In 2010, 12 shoots per replicate tree (three at each cardinal position) were chosen at roughly 4 to $6 \mathrm{ft}$ canopy height, and measured each week, beginning 20 DAFB. All shoots had been headed during dormancy, a standard sweet cherry pruning practice for moderating future crop loads.

Trunk cross-sectional area was calculated from trunk circumference. Measurements were taken at a distance of $20 \mathrm{~cm}$ from the graft union before bloom, at harvest and in the fall following leaf abscission in 2009 and 2010.

YIELD AND FRUIT QUALITY ATTRIBUTES. Full bloom dates were 26 Apr. 2009 and 18 Apr. 2010. Experimental trees were harvested at commercial timing; 24 July 2009 (89 DAFB) and 31 July 2010 (104 DAFB). Individual tree yields were weighed, and a 100 fruit random sample per replication was collected to test fruit quality attributes. Fruit were placed in a cooler and immediately transported to the laboratory. Nondestructive measurements included individual fruit weight, diameter, fruit firmness (Firmtech, Bioworks, Stillwater, OK), and skin color using the CTIFL color scale (Center technique interprofessionel de fruits et légumes, Paris) (2009 only). Fruits were then juiced (Juice Extractor 6001C; Waring Products, New Harford, CT), and $0.5 \mathrm{~mL}$ of juice was pipetted onto a digital refractometer (Palette series, PR-101 $\alpha$; Atago USA, Kirkland, WA) for measurement of SS. Analysis of TA, as malic acid equivalents, was determined using $5 \mathrm{~mL}$ of juice $+10 \mathrm{~mL}$ of deionized water and titrated with $0.1 \mathrm{~N}$ sodium hydroxide to an endpoint $\mathrm{pH}$ of 8.1 using a titrator fitted with an automated sampler (DL15 and Rondolino; Mettler-Toledo, Zurich, Switzerland).

Crop value. Estimates of crop value were made using prices received in 2009 and 2010 for individual size classes of 'Sweetheart' (E. Schrum, personal communication). The frequency distribution of fruit size categories was derived from a random sample of 100 fruit, collected from each replication at harvest. The percentage of total tree yield for each size class was multiplied by its respective price per kilogram, and the totals for all size classes were summed. Average PNW harvest wages paid [\$3 per 20-lb bucket (E. Schrum, personal communication)] were deducted from the price paid per tree to determine crop value.

RETURN BLOOM DYNAMICS. Twenty-five spurs were randomly selected among five shoots (five spurs per 2-year-old segment of shoot) per tree, and the number of reproductive buds per spur recorded. Floral meristems per reproductive bud were determined on a 100-bud sample per replicate tree from 2 -year-old spurs. At the time of sampling, buds were at a development stage between 0 and 1 (i.e., between first swelling and side green). Buds were brought to the laboratory, cross sectioned near the equatorial region of the bud and individual flowers were counted under a stereo-zoom microscope (S6D; Leica Microsystems, Wetzlar, Germany) at 10× magnification.

Pitting experiments. Evaluation of surface pitting was performed on a 50 fruit random sample per replication. Fruits were cooled to $4^{\circ} \mathrm{C}$ following harvest and artificially treated with an instrument designed to mimic the occurrence of an impact injury (Toivonen et al., 2004) (tool was supplied by F. Kappel). Briefly, a 10-g steel rod with a blunt tip positioned in an aluminum stand was dropped from a distance of $60 \mathrm{~mm}$ onto the equatorial region of the fruit surface, four times per fruit (two on each side). Fruits were then immediately placed in regular atmosphere storage and held at $1^{\circ} \mathrm{C}$ for $21 \mathrm{~d}$. Fruits were warmed to room temperature before evaluation. The diameters of individual pits were recorded, and pit diameter was converted to a visual pitting scale, where $1=$ no pitting, 2 = superficial pitting, $3=$ moderate pitting, and $4=$ severe pitting, based on the published regression equation describing the relationship (Toivonen et al., 2004).

Growing DEgree DAYs. Calculation of growing degree days (GDD) was performed each year using temperature data generated by an IFPNet meteorological station (Wy'East RC\&D, 2009), located within $100 \mathrm{~m}$ 
from the experimental orchard. Accumulation of GDD from full bloom was calculated using the average daily minimum and maximum temperatures, and a low temperature threshold of $50^{\circ} \mathrm{F}$.

Statistical analysis. Statistical analyses were performed using SAS (version 9.2; SAS Institute, Cary, NC). Treatment means of yield, fruit size, fruit quality (including skin color and pitting incidence), TCSA, number of buds per fruiting spur, number of flowers per reproductive bud, and number of fruit per size class were analyzed using analysis of variance (PROC GLM). Significance was tested at $P \leq 0.05$. Mean separation was determined by Fisher's protected least significant difference test. Fruit and shoot growth data were plotted $\pm 1 \mathrm{SE}$. Regression analysis (PROC REG) was used to analyze the relationship between crop load and average fruit size.

\section{Results}

FRUIT, SHOOT AND TRUNK GROWTH. In 2009, cumulative growth of control fruit was significantly less than $\mathrm{T} 1$ and $\mathrm{T} 2$ treatments by 30 DAFB (Fig. 1A). During the period of rapid fruit expansion (59-73 DAFB), control fruit had a significantly lower growth rate than the other treatments (data not shown). Tl fruit size was significantly greater than the control at 60 DAFB and was intermediate between control and T2 for the remainder of the season (Fig. 1A). In contrast, 2010 treatment effects on fruit growth did not manifest until 89 $\mathrm{DAFB}$, and were observed for $\mathrm{T} 2$ fruit only (Fig. 1B). A difference in fruit size between years was observed on 30 DAFB (Fig. 1A and 1B).

Current season extension shoot growth was inversely related to crop load level (Fig. 2). Our sample population was at the lower limit for detecting treatment effects, as evidenced by the large SE for individual treatment means, though significant differences among treatments were observed on 23 DAFB $(P=0.0003)$, and on each successive sampling date (data not shown).

Trunk growth was significantly affected by crop load level in the preharvest period, -30 DAFB to harvest, in 2009 only (data not shown). Trunk cross-sectional area increase (TCSAi) was $4 \%, 7.9 \%$, and $7.2 \%$ for control, $\mathrm{T} 1$, and $\mathrm{T} 2$, respectively $(P=$

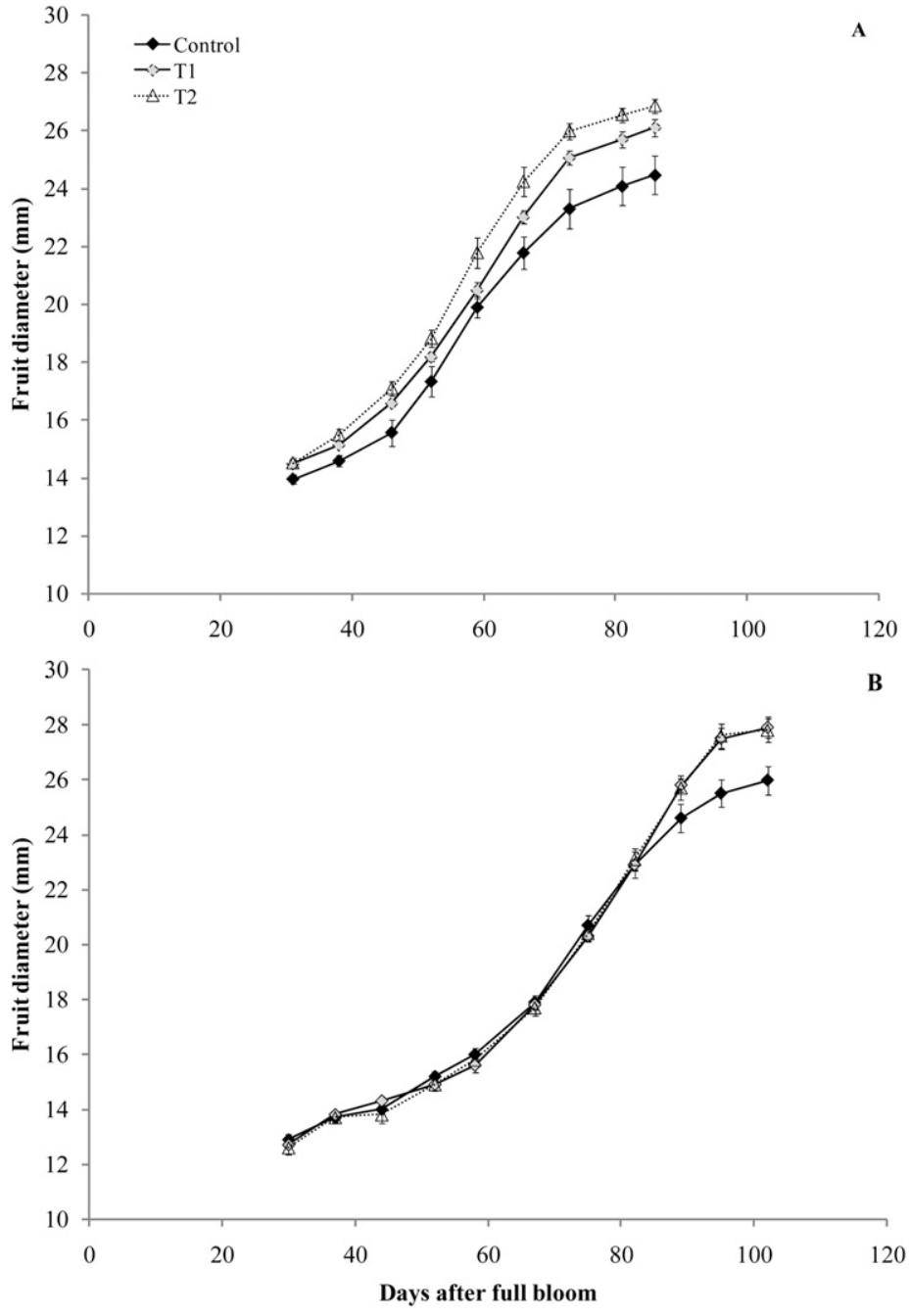

Fig. 1. Effect of crop load treatment on cumulative fruit size of 9- and 10-year-old 'Sweetheart' /'Mazzard' sweet cherry trees in (A) 2009 and (B) 2010, respectively. Whole trees were adjusted to three different crop load levels before bloom: control = unthinned, $\mathrm{Tl}=$ removal of half of the reproductive buds from all spurs, and T2 = removal of all but one reproductive bud from all spurs. Values are the means $\pm 1 \mathrm{SE}$ of five replicate trees $(n=15) ; 1 \mathrm{~mm}=0.0394$ inch.

0.008; data not shown). During the postharvest interval, from harvest to leaf abscission, TCSAi was $5 \%$ for control, $2.8 \%$ for $\mathrm{T} 1$, and $3.5 \%$ for $\mathrm{T} 2$ $(P=0.47$; data not shown $)$. In 2010 , total annual percent increase was nearly half that of 2009, and TCSAi did not significantly differ among treatments during either interval; $2.8 \%, 4 \%$, and $3.8 \%$ during the preharvest period for control, T1, and T2 $(P=0.31)$, and $1.9 \%, 1.6 \%$, and $2.4 \%$ during the postharvest period for control, $\mathrm{T} 1$, and $\mathrm{T} 2$ $(P=0.44)$, respectively.

YIELD, FRUIT QUALITY, AND SURFACE PITTING. Bud thinning significantly affected total tree yield, average fruit size, SS, TA, and skin color (CTIFL in 2009 only) in 2009 and
2010 (Table 1). Fruit firmness was significantly affected in 2010 , but not 2009 (Table 1). Relative to the control, total tree yields of $\mathrm{T} 1$ and $\mathrm{T} 2$ were reduced by $40 \%$ and $54 \%$ in 2009 , and $36 \%$ and $54 \%$ in 2010 , respectively. For all fruit attributes evaluated, significant improvements were detected for $\mathrm{Tl}$ relative to the control, but further improvement with greater severity of crop load reduction by T2 was not consistently observed (Table 1). Despite the improvement in fruit quality, lighter crop loads did not translate into reduced surface pitting (Table 1). In 2009, pitting severity was slightly reduced for $\mathrm{T} 2$, albeit nonsignificantly. Irrespective, all treatments had a relatively low visual pitting 


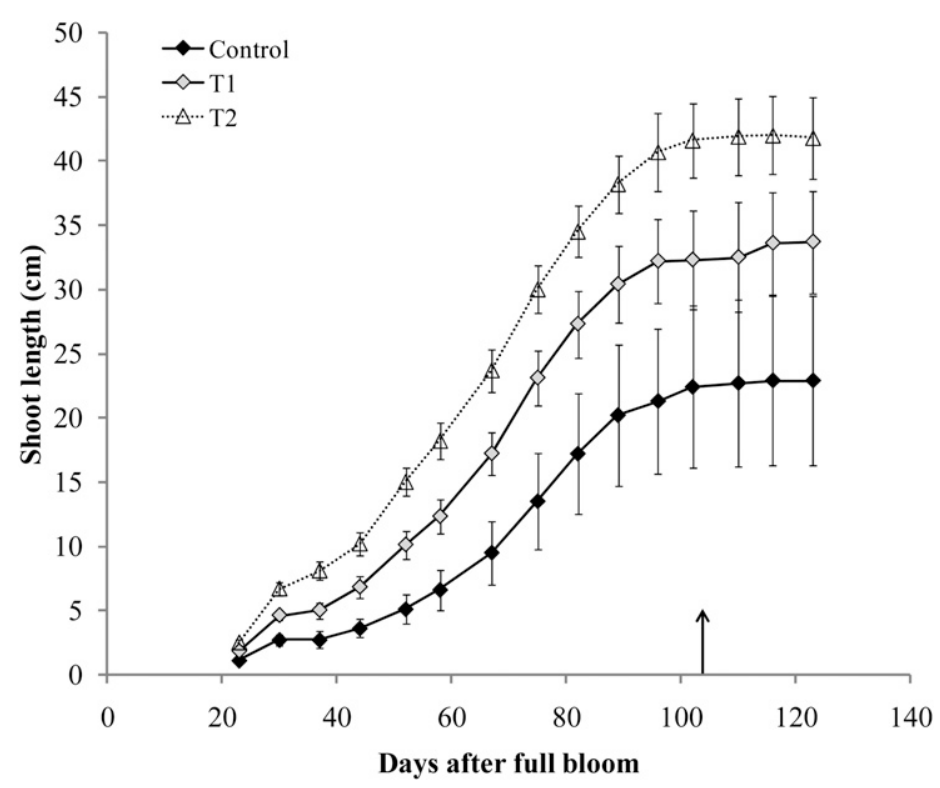

Fig. 2. Effect of crop load treatment on cumulative shoot growth of 9-year-old 'Sweetheart' /'Mazzard' sweet cherry trees in 2010. Whole trees were adjusted to three different crop load levels before bloom: control = unthinned, $\mathrm{Tl}=$ removal of half of the reproductive buds from all spurs, and T2 $=$ removal of all but one reproductive bud from all spurs. Arrow on the $x$-axis signifies harvest date. Values are the means \pm 1 SE of five replicate trees $(n=12) ; 1 \mathrm{~cm}=0.3937$ inch.

score $(2$-year range between 1.6 and 2.2; Table 1).

The distribution of harvested fruit within size-class categories was markedly affected by crop load level (Fig. 3A and $3 \mathrm{~B})$. Greater variation was observed for control fruit (i.e., more evenly distributed over an increased number of size categories), in addition to a relatively high proportion of fruit deemed unmarketable $(21.4 \mathrm{~mm}$ and smaller); $18 \%$ compared with $<1 \%$ for T1 and T2 (Fig. 3A and 3B). When averaged across years $84 \%$, $71 \%$, and $23 \%$ of total yields comprised target fruit, $28.2 \mathrm{~mm}$ and larger, for $\mathrm{T} 2, \mathrm{~T} 1$, and control trees, respectively. In 2009, the net effect of increasing the percentage of large fruit due to $\mathrm{Tl}$ crop load adjustment (Fig. 3A) was a higher crop value relative to the control (Table 2 ), despite a $40 \%$ yield reduction (Table 1 ). However, further improvement in the percentage of large fruit did not offset the overall low yields of T2. Consequently T2 had the lowest crop value per tree compared with $\mathrm{Tl}$ and control (Table 2). Crop value per tree in 2010 was highest for control trees (Table 2), despite the relatively high percentage of unmarketable fruit (i.e., $18 \%$ of 21.4-mm and smaller fruit), closely followed by $\mathrm{T} 1$, and least for $\mathrm{T} 2$.
Average fruit size at harvest was significantly, negatively correlated with crop load $\left(r^{2}=0.75, P<\right.$ 0.0001 ), when expressed as number of fruit per square centimeter of TCSA (Fig. 4).

ReTURN BLOOM DYNAMics. Crop load level was negatively related to both the number of reproductive buds per spur and floral meristems per reproductive bud (Fig. 5). Fruit density affected return bloom similarly in both years. When 2010 and 2011 return bloom data were pooled, significantly more floral buds per fruiting spur were observed for $\mathrm{T} 1$ and $\mathrm{T} 2$ relative to controls ( $21 \%$ and $33 \%$, respectively), though differences between the two reduced crop load treatments were not significant. The relationship between crop load and flower number per reproductive bud was highly significant $(2009, P=0.0003 ; 2010, P=$ 0.0014 ), but only T2 had statistically more flowers per bud (data not shown).

GROWING DEGREE DAYS. In 2009 1526 GDD accumulated between full bloom and harvest (i.e., 89-d period). By contrast, 998 GDD accumulated between full bloom and 89 DAFB in 2010 and 1367 between full bloom and harvest (data not shown).

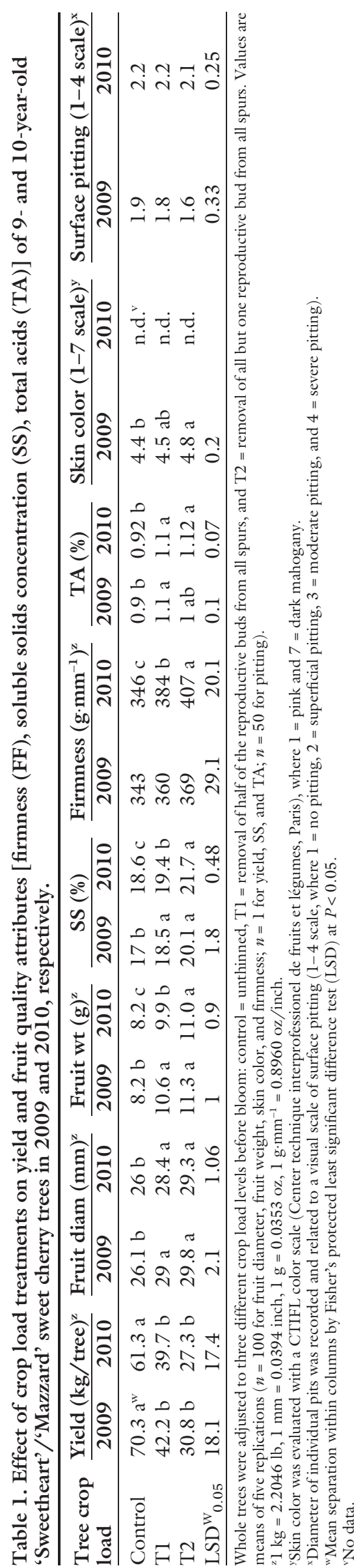




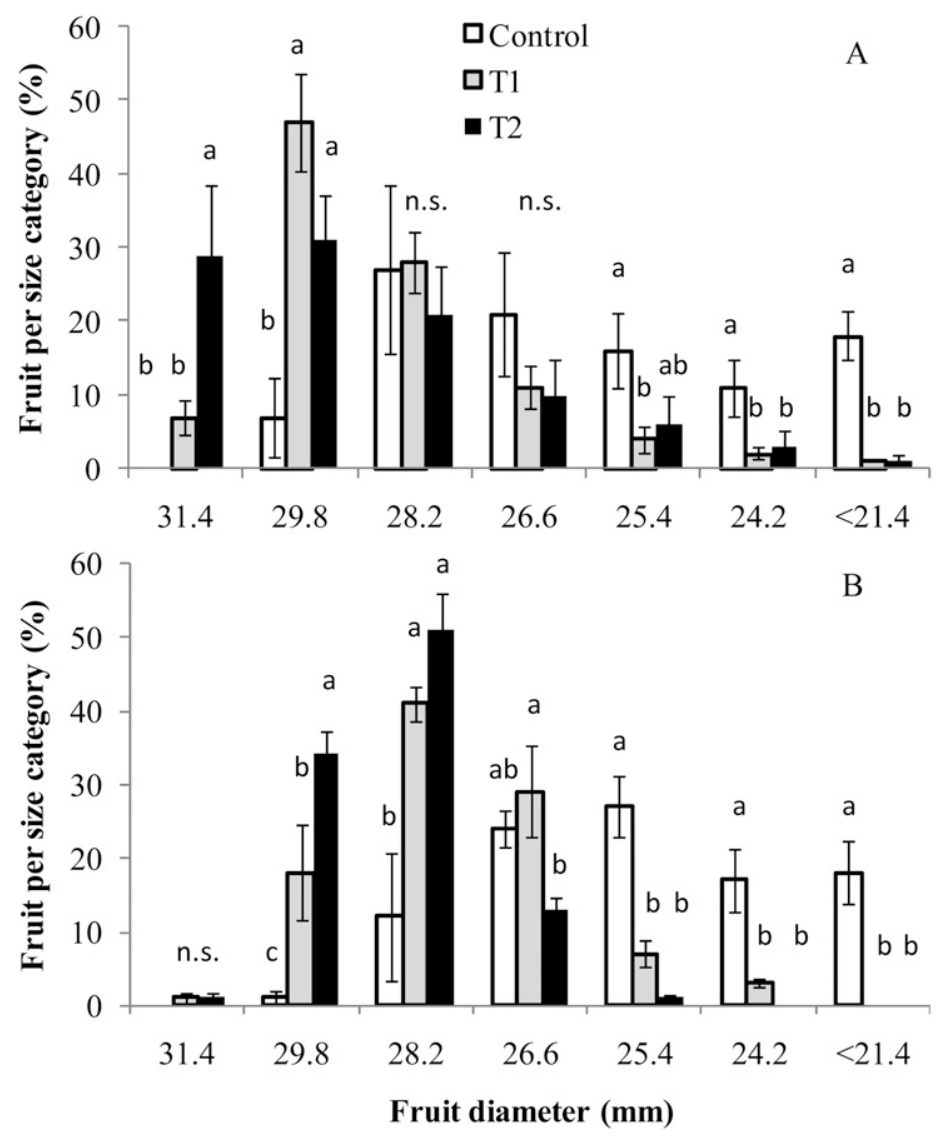

Fig. 3. Effect of crop load treatment on fruit size distribution of 9- and 10-year-old 'Sweetheart' /'Mazzard' sweet cherry trees in (A) 2009, and (B) 2010, respectively. Whole trees were adjusted to three different crop load levels before bloom: control = unthinned, $\mathrm{T} 1 \mathrm{l}=$ removal of half of the reproductive buds from all spurs, and T2 = removal of all but one reproductive bud from all spurs. Data are means $\pm 1 \mathrm{SE}$ of five replicate trees $(n=100)$. Mean separation within a size category by Fisher's protected least significant difference test at $P<0.05 ;$ n.s. $=$ not significant, $1 \mathrm{~mm}=$ 0.0394 inch.

Table 2. Effect of crop load treatment on 2009 and 2010 crop value of 'Sweetheart' /'Mazzard' sweet cherry trees.

\begin{tabular}{lcc}
\hline Crop load & 2009 crop value $(\$ /$ tree $)$ & 2010 crop value $(\$ /$ tree $)$ \\
\hline Control & $\$ 125.36$ & $\$ 189.94$ \\
T1 & $\$ 141.78$ & $\$ 181.99$ \\
T2 & $\$ 106.50$ & $\$ 138.15$
\end{tabular}

Crop values are based on 2009 and 2010 'Sweetheart' prices received per size class. Frequency distributions of fruit size classes were derived from a 100 fruit sample per replication (data are shown in Fig. 3). The portion of tree yield (kilograms) per size class was multiplied by its respective price and summed. Harvest costs were then subtracted based on an average regional harvest rate of $\$ 3$ per $20 \mathrm{lb}(9.1 \mathrm{~kg})$ of yield. Whole trees were adjusted to three different crop load levels before bloom: control = unthinned, $\mathrm{Tl}=$ removal of half of the reproductive buds from all spurs, and T2 = removal of all but one reproductive bud from all spurs.

\section{Discussion}

Manual bud removal to manipulate fruit density established several consistent and uniform crop load levels that allowed the interactions among fruit number, fruit quality, and vegetative growth to be studied. Yield, fruit size, and annual price per size class were used to derive crop value to identify whether crop load reduction could improve profitability of 'Sweetheart' / Mazzard' orchards. The range of crop load levels tested and their associated crop values for two considerably different marketing years can aid in deriving future crop load targets once effective fruit thinning strategies are developed.

Previous studies have characterized the dry matter accumulation and/ or photoassimilate allocation among sweet cherry sinks during growth and development (Ayala, 2004; Kappel, 1991; Roper et al., 1987; Whiting and Lang, 2004), but data describing cumulative sweet cherry fruit growth in response to crop load are limited. In the present study, 2009 control trees had significantly smaller fruit size by $30 \mathrm{DAFB}$ than either $\mathrm{Tl}$ or $\mathrm{T} 2$, indicating that early competition for carbohydrates among fruit was quite high. Within the first month from bloom, growth and development of fruit, spur leaves, and shoots rely heavily on storage carbohydrates (Ayala, 2004). In the case of 2009, these were likely insufficient to meet the resource demands of developing fruitlets of control trees. The final few weeks of fruit growth represents the period of greatest sink demand due to the convergence of multiple active growth processes (Flore and Layne, 1999), the effects of which can be seen by the relatively lower slope of control fruit compared with other treatments following 59 DAFB (Fig. 1A).

Control tree yields in 2010 were $87 \%$ of 2009 . On the basis of an average fruit size of $8.2 \mathrm{~g}$ (Table 1 ), this represents 1100 fewer fruit per tree. The high fruit number per tree in 2009 may have reduced 2010 return bloom (Fig. 5) and contributed to the lower fruit set of control trees in 2010. However, fruit size of control fruit at $30 \mathrm{DAFB}$ was reduced by $\approx 10 \%$ in 2010 relative to 2009 (Fig. $\mathrm{IA}$ and $\mathrm{IB}$ ). In fact, $\mathrm{T} 1$ and $\mathrm{T} 2$ fruit were $\approx 15 \%$ smaller in 2010 compared with 2009, regardless of the nearly identical tree yields of these treatments between years (Table 1 ). These differences may be associated with fewer GDD accumulated by 30 DAFB in 2010 compared with 2009 (246 and 330 GDD, respectively). Peach (Prunus persica) fruit growth and seasonal development were highly dependent on GDD accumulation during the first month from full bloom (Lopez and DeJong, 2008). The authors hypothesized that rapid accumulation of GDD during early fruit development increases the fruit's daily demand for growth resources, ultimately limiting its daily growth potential; a phenomenon that was augmented by higher crop loads (Lopez and DeJong, 2008; Pavel and DeJong, 1993). Though we did not investigate fruit growth rates 


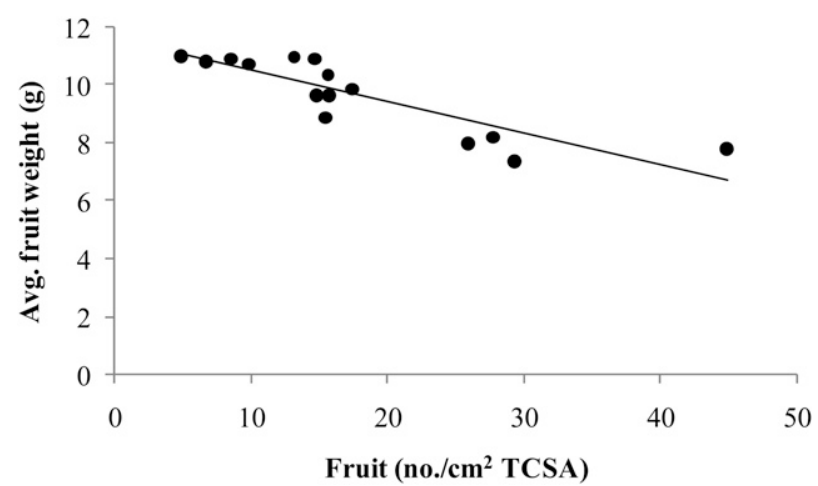

Fig. 4. Effect of crop load on average fruit size at harvest of 10-year-old 'Sweetheart' /'Mazzard' sweet cherry trees. Linearity was tested using PROC REG of SAS (version 9.2; SAS Institute, Cary, NC). Regression equation: $y=-0.1089 x+$ 11.616, $r^{2}=0.75, P<0.0001$. Each data point represents a single replicate tree $(n=$ 100 for average fruit size); TCSA = trunk cross-sectional area, 1 fruit $/ \mathrm{cm}^{2}=6.4516$ fruit $/$ inch $^{2}, 1 \mathrm{~g}=0.0353 \mathrm{oz}$.
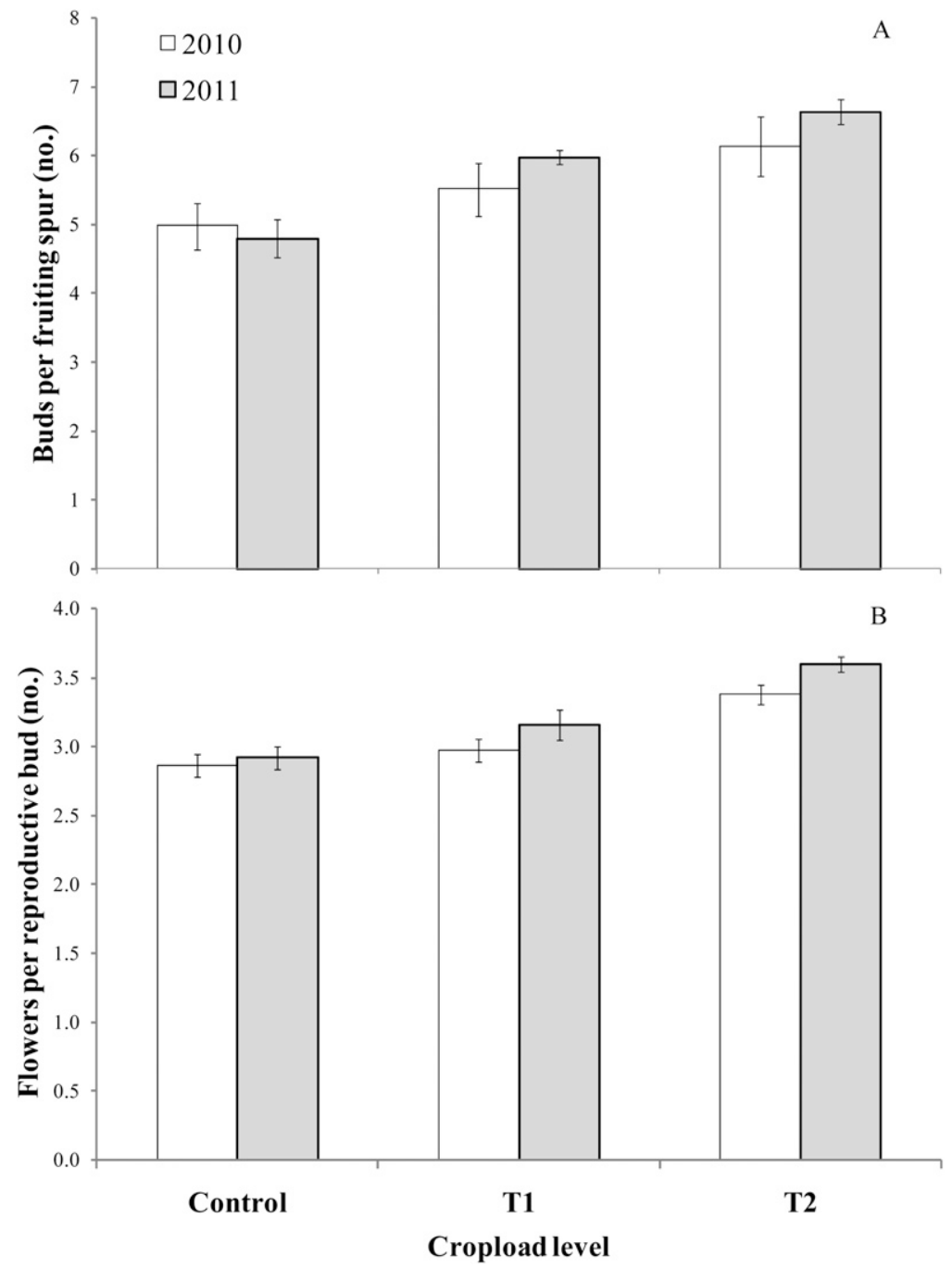

Fig. 5. Effect of 2009 and 2010 crop load treatments on 2010 and 2011 reproductive bud number (A) per spur and (B) floral meristems per reproductive bud from 2-year-old shoot segments of 'Sweetheart' /'Mazzard' sweet cherry trees. Whole trees were adjusted to three different crop load levels before bloom: control = unthinned, $\mathrm{Tl}=$ removal of half of the reproductive buds from all spurs before bloom, and T2 = removal of all but one reproductive bud from all spurs before bloom. Data are means \pm 1 SE of five replicate trees $(n=25$ for $\mathrm{A}, n=50$ for $\mathrm{B})$. from 0 to $30 \mathrm{DAFB}$ in either year, the combination of higher temperatures and heavier fruit set in 2009 (Fig. 1A) could have exacerbated the carbon supply and demand imbalance of control trees. Since organ development depends on temperature, lower temperatures in 2010 likely contributed to a longer season $(+15 \mathrm{~d})$, relative to 2009. Conversely, the combination of lower GDD accumulation and crop load level in 2010 may have ameliorated the effect of crop load treatment on fruit size, although control tree yields in 2010 were still quite high $(\approx 11$ tons/acre). Irrespective, significant treatment effects on fruit growth in 2010 were not evident until 89 DAFB (Fig. 1B).

Shoot growth, however, was markedly reduced in 2010 , early, and in proportion to crop load (Fig. 2), indicating that 'Sweetheart' shoots were more sensitive than fruit to heavy crop loads during late Stage I and Stage II of fruit development. Shoot growth responded negatively to crop load level earlier and to a greater extent than a previous report using 'Bing' on the highly productive and dwarfing 'Gisela 5' rootstock (Whiting and Lang, 2004); however, the 'Sweetheart' trees of the present study had markedly more fruit per tree (7475 vs. 3081 fruit per tree). Our shoot length data, however, do not represent the mean shoot length throughout the entire canopy since measurements were taken at a distance of $\approx 5$ to $6.5 \mathrm{ft}$ from ground level and tree height exceeded $13 \mathrm{ft}$. Shoot vigor is positively related to tree height, and this was indeed observed within experimental trees.

Trunk growth was affected by crop load in 2009, but not in 2010 (data not shown). During the 2009 preharvest interval, TCSAi was nearly double that of control for both reduced crop load treatments (data not shown). In 2010, trunk growth was minimal $(3 \%$ to $4 \%)$ during the preharvest period and did not differ among treatments (data not shown). Kappel (1991) showed that vegetative components (i.e., mainly wood) had greater relative sink strength compared with fruit and comprised the greatest percentage of annual dry matter; however, Whiting and Lang (2004) confirmed that during fruit growth and development, trunks were relatively weak sinks for carbohydrates. For 'Sweetheart', even in combination with 
a highly vigorous rootstock, high fruit densities limited dry matter accumulation in vegetative organs.

The improvements in intrinsic fruit quality that were observed for low crop load treatments (Table 1 ) may be less relevant to cherry orchardists' net returns. On the contrary, high incidence of surface pitting can severely impact sweet cherry crop quality and value. 'Sweetheart' is highly susceptible to surface pitting, and observations from both the literature (Facteau, 1982; Spayd et al., 1986) and industry (B. Bailey, personal communication) sustain the general belief that crop load is positively related to pitting incidence of sweet cherry. In our experiments, surface pitting of 'Sweetheart' was unaffected by crop load level (Table 1). Further, overall visual rating of pitting severity was quite low $(\approx 2.2$; see Table 1$)$, irrespective of crop load. Although the magnitude of crop load clearly affected cherry fruit quality [FF, size, and SS (Table 1)], these attributes, acting independently or through interactions, do not appear to be strongly associated with pitting. Toivonen et al. (2004) developed a predictive model to describe pitting using firmness, fruit respiration at harvest, and weight loss during storage. However, depending on the cultivar, $\approx 30 \%$ of the variability in pitting could not be explained by the model and they concluded that there were likely additional unidentified factors contributing to the disorder. Other studies have similarly linked firmness with pitting incidence, in addition to SS and fruit size (Facteau and Rowe, 1979; Spayd et al., 1986). In our study, firmness was significantly reduced as crop load increased (Table l); however, firmness values of control fruit were relatively high $(\approx 350$ $\mathrm{g} \cdot \mathrm{mm}^{-1}$ ). That firmness of our control fruit exceeded values observed in the aforementioned studies could partially explain the poor relationship we observed between firmness and pitting incidence (data not shown). Moreover, SS did not change appreciably during the $21 \mathrm{~d}$ of storage (data not shown) suggesting that water loss, and hence weight loss, was minimal (Drake and Elfving, 2002).

The 2009 sweet cherry crop was the highest yielding crop in PNW history (B.J. Thurlby, personal communication). Consequently, an oversupply of fruit led to poor grower returns. In such a year, crop load management, despite the use of low productive rootstocks such as ' $\mathrm{Maz}$ zard', improved 'Sweetheart' crop value per tree. The $\approx \$ 16$ net increase per tree equates to $\$ 2622$ per acre profits, at the tree density of the orchard specified in this study, not including the cost of thinning. For comparison, the cost of chemical thinning of modern commercial apple orchards is roughly $\$ 500$ per acre; however, depending on the thinning program implemented, costs can range from $\$ 250$ to $\$ 750$ per acre (T. Auvil, personal communication). The wide range in costs is influenced by the number of applications, products selected (i.e., material costs), cultivar, and seasonal interactions between environmental and biological factors. Interestingly, $2010 \mathrm{crop}$ value per tree was not improved by crop reduction (Table 2). Yields of T1 and T2 were nearly identical in both years, but improved fruit quality of T1 and T2 (Table 1) did not outweigh the higher total yields of control trees in 2010. In addition, $18 \%$ of the total yield of control trees comprised fruit that was too small to receive fresh market cherry returns. These results agree with the findings of Whiting et al. (2005a), that under the current sweet cherry pricing structure there is economic incentive for producing a large volume of mediumsized fruit. Relative to 2009 , less supply in 2010, and hence, higher prices per unit (especially for larger size classes) contributed to the disparity between years. Clearly these relationships vary yearly (Table 2 ). In a 9-year study characterizing crop load and fruit quality relationships of a lowdensity 'Bing' orchard, Proebsting and Mills (1981) observed marked yearly shifts in production. Fruit quality in that study generally held an inverse relationship with crop load, and it was concluded that regulation of crop load would benefit sweet cherry quality; however, crop values were not reported in that study.

Although uniform crop load reduction of 'Sweetheart' /'Mazzard' did not translate into improved crop value per tree in the second year of the study, other techniques could be implemented to markedly reduce the large percentage of $21.4-\mathrm{mm}$ and smaller fruit. Removal of weak, pendant wood, densely populated with fruiting spurs as practiced on combinations of high yielding cherry cultivars and precocious, productive 'Gisela' rootstocks (Lang, 2005; Long, 2007) is a viable strategy for crop management of 'Sweetheart' /'Mazzard'. Prior work has demonstrated the preferential delivery of carbohydrates to fruit in close proximity to nonfruiting leaf populations under high crop load conditions (Ayala, 2004). We have observed poor final fruit size of fruit residing on weak limbs with high fruit density, despite overall low scaffold or wholecanopy crop loads (T.C. Einhorn, unpublished). These observations indicate that branches behave as semiautonomous units, and local source:sink imbalances cannot be corrected by high leaf area to fruit ratios of adjacent limbs.

The experimental procedure used in our study to balance crop load was not intended as a commercial thinning regime (impractical due to high costs of implementation), yet the results identify how elimination of fruit, by a consistent, uniform method affects vegetative growth, fruit quality, yield, and crop value. The importance of managing sweet cherry crop loads on productive and precocious, dwarfing rootstocks has been previously documented (Whiting and Lang, 2004). On the basis of our data, 'Sweetheart' /'Mazzard' is highly productive and profitable under the current pricing structure, and removal of weak wood should supplement the percentage of marketable fruit. The high productivity of 'Sweetheart' / Mazzard' is ideal for moderate density plantings, and does not appear to require the additional annual costs and challenges of crop load management.

\section{Literature cited}

Ayala, M. 2004. Carbon partitioning in sweet cherry (Prunus avium L. ) on dwarfing, precocious rootstocks, during fruit development. Michigan State Univ., East Lansing, PhD Diss.

Drake, S.R. and D.C. Elfving. 2002. Indicators of maturity and storage quality of 'Lapins' sweet cherry. HortTechnology 12:687-690.

Edin, M., A. Garcin, J. Lichou, and J.M. Jourdain. 1996. Influence of dwarfing cherry rootstocks on fruit production. Acta Hort. 410:239-245.

Facteau, T.J. 1982. Relationship of soluble solids, alcohol-insoluble solids, fruit calcium, and pectin levels to firmness and 
surface pitting in 'Lambert' and 'Bing' sweet cherry fruit. J. Amer. Soc. Hort. Sci. 107:151-154.

Facteau, T.J. and K.E. Rowe. 1979. Factors associated with surface pitting of sweet cherry. J. Amer. Soc. Hort. Sci. 104:706-710.

Facteau, T.J., N.E. Chestnut, and K.E. Rowe. 1983. Relationship between fruit weight, firmness, and leaf/fruit ratio in Lambert and Bing sweet cherries. Can. J. Plant Sci. 63:763-765.

Flore, J.A. and D.R. Layne. 1999. Photoassimilate production and distribution in cherry. HortScience 34:1015-1019.

Kappel, F. 1991. Partitioning of aboveground dry matter in 'Lambert' sweet cherry trees with or without fruit. J. Amer. Soc. Hort. Sci. 116:201-205.

Kappel, F. and G. Lang. 2008. Performance of the NC-140 regional sweet cherry rootstock trial planted in 1998 in North America. Acta Hort. 795:317320 .

Lane, W.D. and R.A. MacDonald. 1996. Sweetheart sweet cherry. Can. J. Plant Sci. 76:161-163.

Lang, G.A. 2000. Precocious, dwarfing, and productive-how will new cherry rootstocks impact the sweet cherry industry? HortTechnology 10:719-725.

Lang, G.A. 2005. Underlying principles of high density sweet cherry production. Acta Hort. 667:325-335.

Long, L. 2007. Four simple steps to pruning cherry trees on Gisela and other productive rootstocks. Oregon State Univ., PNW 592.

Lopez, G. and T. DeJong. 2008. Using growing degree hours accumulated thirty days after bloom to help growers predict difficult fruit sizing years. Acta Hort. 803:175-180.

Pavel, E.W. and T.M. DeJong. 1993. Source- and sink-limited growth periods of developing peach fruits indicated by relative growth rate analysis. J. Amer. Soc. Hort. Sci. 118:820-824.

Perry, R.L., G. Lang, R. Andersen, L. Anderson, A. Azarenko, T. Facteau, D. Ferree, A. Gaus, F. Kappel, F. Morrison, C. Rom, T. Roper, S. Southwick, G. Tehrani, and C. Walsh. 1998. Performance of the NC-140 cherry rootstock trials in North America. Acta Hort. 468:291-296.

Porritt, S.W., L.E. Lopatecki, and M. Meheriuk. 1971. Surface pitting-a storage disorder of sweet cherries. Can. J. Plant Sci. 51:409-414.

Proebsting, E.L. 1990. The interaction between fruit size and yield in sweet cherry. Fruit Var. J. 44:169-172.

Proebsting, E.L. and H.H. Mills. 1981. Effects of season and crop load on maturity characteristics of 'Bing' cherry. J. Amer. Soc. Hort. Sci. 106:144-146.

Roper, T.R. and W.H. Loescher. 1987. Relationships between leaf area per fruit and fruit quality in 'Bing' sweet cherry. HortScience 22:1273-1276.

Roper, T.R., W.H. Loescher, J. Keller, and C.R. Rom. 1987. Sources of photosynthate for fruit growth in 'Bing' sweet cherry. J. Amer. Soc. Hort. Sci. 112:808812.

Schoedl, K., A. Denk, S. Hummelbrunner, P. Modl, and A. Forneck. 2009. No improvement in fruit quality through chemical flower thinning in sweet cherry (Prunus avium L.). J. Sci. Food Agr. 89:1236-1240.
Spayd, S.E., E.L. Proebsting, and L.D. Hayrynen. 1986. Influence of crop load and maturity on quality and susceptibility to bruising of 'Bing' sweet cherries. J. Amer. Soc. Hort. Sci. 111:678-682.

Thompson, J.F., J.A. Grant, E.M. Kupferman, and J. Knutson. 1997. Reducing sweet cherry damage in postharvest operations. HortTechnology 7:134-138.

Toivonen, P.M.A., F. Kappel, S. Stan, D.L. McKenzie, and R. Hocking. 2004. Firmness, respiration, and weight loss of 'Bing', 'Lapins' and 'Sweetheart' cherries in relation to fruit maturity and susceptibility to surface pitting. HortScience 39:1066-1069.

Whiting, M.D. and G.A. Lang. 2004. 'Bing' Sweet Cherry on the dwarfing rootstock 'Gisela 5': Thinning affects fruit quality and vegetative growth but not net $\mathrm{CO}_{2}$ exchange. J. Amer. Soc. Hort. Sci. 129:407-415.

Whiting, M.D. and D. Ophardt. 2005. Comparing novel sweet cherry crop load management strategies. HortScience 40:1271-1275.

Whiting, M.D., D. Ophart, O. Lenahan, and D. Elfving. 2005a. Managing sweet cherry crop load: New strategies for a new problem. Compact Fruit Tree. 38:52-58.

Whiting, M.D., G. Lang, and D. Ophart. $2005 \mathrm{~b}$. Rootstock and training system affect sweet cherry growth, yield, and fruit quality. HortScience 40:582-586.

Whiting, M.D., J.R. McFerson, and D. Ophardt. 2006. Chemical blossom thinners vary in their effect on sweet cherry fruit set, yield, fruit quality, and crop value. Hort Technology 16:66-70.

Wy'East RC\&D. 2009. Integrated fruit production. IFPNet. 16 Apr. 2011. <http://www.integratedfruitproduction. com/IFPNET/tabid/92/Default.aspx>. 